\title{
Geographical Indications between Trade, Development, Culture, and Marketing: Framing a Fair(er) System of Protection in the Global Economy?
}

Irene Calboli

Texas A\&M University School of Law, irene.calboli@gmail.com

Follow this and additional works at: https://scholarship.law.tamu.edu/facscholar

Part of the Intellectual Property Law Commons, and the International Trade Law Commons

\section{Recommended Citation}

Irene Calboli, Geographical Indications between Trade, Development, Culture, and Marketing: Framing a Fair(er) System of Protection in the Global Economy?, in Geographical Indications at the Crossroads of Trade, Development, and Culture Read: Focus on Asia-Pacific 3 (Irene Calboli \& Wee Loon Ng-Loy eds., 2017).

Available at: https://scholarship.law.tamu.edu/facscholar/919

This Book Section is brought to you for free and open access by Texas A\&M Law Scholarship. It has been accepted for inclusion in Faculty Scholarship by an authorized administrator of Texas A\&M Law Scholarship. For more information, please contact aretteen@law.tamu.edu. 


\title{
Geographical Indications between Trade, Development, Culture, and Marketing: Framing a Fair(er) System of Protection in the Global Economy?
}

\author{
Irene Calboli*
}

\section{INTRODUCTION}

This chapter analyzes some of the topics on the current debate involving geographical indications (GIs) of origin that will be further elaborated by the contributors to this volume from a variety of perspectives and angles. As the title indicates, this volume focuses on GI protection "at the crossroads of trade, development, and culture," with a specific focus on the countries in the AsiaPacific region. This choice is due primarily to the fact that the analysis of issues related to GI protection in this region is, to date, not as extensive as the analysis in other regions, particularly in the Western world. This volume intends to fill this gap and aims, in particular, at analyzing the potential benefits, but also related problems, of GI protection for local and national development in AsiaPacific countries. Trade- and culture-related issues, primarily issues related to the conservation and promotion of local culture and cultural diversity, are also central to the contributions to this volume. As the opening contribution of this volume, this chapter then aims at setting the stage and framing the context for other authors by offering an overview of the status of the GI debate, as well as emphasizing some of the trends that have become salient features of this debate in Asia-Pacific, and worldwide. These trends are, in particular, the following: the globalization of the GI debate beyond Western countries and beyond a "wine and cheese" agenda, or trade war, between primarily Western

* Lee Kong Chian Fellow, Visiting Professor and Deputy Director, Applied Research Centre for Intellectual Assets and the Law in Asia, Singapore Management University School of Law; Professor of Law, Texas A\&M University School of Law. This chapter builds on my previous publications in this area. 
interests; the increased attention for the potential benefits of GI protection by developing countries and the often neglected attention to the potential problems associated with GI protection for local producers in these countries; and the increasing loosening of the definition of GIs as symbols of true geographical origin in favor of a definition granting exclusive rights based on the "historical reputation" of GIs.

Building on this premise, Section 2 starts by discussing how, after almost a century of limited attention at the international level, GIs have become one of the hottest topics in international intellectual property law today. Born out of the French tradition in the nineteenth century, and originally reserved to identify, and protect, the geographical origin of wines against counterfeits, GI protection was later accepted by other European countries and eventually by the European Union (EU). Then, from Europe, GIs become a global phenomenon and a topic of international controversy in the past two decades. In particular, GIs were one of the hot issues at the negotiating table that led to the creation of the World Trade Organization (WTO) in the late 1980s and early 199os. Discussions over GIs continued to dominate part of the WTO Doha Development Agenda, even though WTO Members never reached any agreement on the issue. ${ }^{1}$ Still, despite the lack of consensus at the international level, an increasing number of countries became interested in GIs in the following years. This interest reached beyond Western countries. In particular, countries in Asia, Africa, and South America have adopted, to date, national policies on GIs and taken part in the discussion of the WTO Doha Development Agenda. In the past decade, provisions related to GI protection have also become an important component of bilateral and plurilateral international trade agreements (FTAs) between countries from all continents. ${ }^{2}$ To some extent, this is the result of the pressure exerted by the $\mathrm{EU}$ in its attempt to export a pro-GI protection agenda outside Europe. But many countries have become interested in GIs regardless of this pressure. In 2015, discussions over GI protection also led to the adoption of the Geneva Act of the Lisbon Agreement for the Protection of Appellations of Origin and their International Registration (Geneva Act) under the auspices of the World

1 Agreement on Trade-Related Aspects of Intellectual Property Rights, April 15, 1994, Marrakesh Agreement Establishing the World Trade Organization, Annex 1C, 1869 U.N.T.S 299 [hereinafter TRIPS]; World Trade Organization, Ministerial Declaration of November 14, 2001, WTO Doc. WT/MIN(o1)/DEC/1, 41 I.L.M. 746 (2002) [hereinafter Doha Declaration].

2 See infra Section 2. 
Intellectual Property Organization. ${ }^{3}$ Even though the Geneva Act was, at large, the result of Western pro-GI diplomacy, it was supported by countries outside Europe.

Moving from the international to the national level, Section 3 first reports that several jurisdictions in Asia-Pacific have currently adopted national sui generis systems for GI protection. These national laws are largely modelled after the system currently adopted in the EU. Countries that have implemented sui generis systems include, to date, Japan, South Korea, Bangladesh, Sri Lanka, Australia, Cambodia, Malaysia, and Singapore. ${ }^{4}$ Several countries in Asia-Pacific have also established, or are discussing the establishment of national GI registries to register both national and foreign GIs. ${ }^{5}$ Countries that already operate national GI registries in Asia-Pacific include Cambodia, India, Indonesia, Malaysia, Thailand, Vietnam, and other countries. ${ }^{6}$ Several of the contributors to this volume explain in detail the laws, including the national reforms, which have been adopted in these countries. Building on these descriptions, Section 3 focuses on the potential benefits of GIs for socioeconomic development as well as for safeguarding national cultural heritage in Asia-Pacific, and in general. ${ }^{7}$ However, Section 3 highlights that GIs do not per se constitute a magic recipe, and that the long-term success of GI products depends largely on local producers controlling and maintaining the quality of the products, and developing savvy marketing plans. This point is reiterated by many of the contributors to this volume, and is probably the most important observation directed to GI producers, local and regional communities.

3 World Intellectual Property Organization (WIPO), Geneva Act of the Lisbon Agreement on Appellations of Origin and Geographical Indications and Regulations under the Geneva Act of the Lisbon Agreement on Appellations of Origin and Geographical Indications, WIPO Doc. LI/DC/19 (May 20, 2015) [hereinafter, Geneva Act]. For the original version of the Lisbon Agreement, see Lisbon Agreement for the Protection of Appellations of Origin and their International Registration, art. 2(1), October 31, 1958, as revised July 14, 2967, 923 U.N.T.S. 205 [hereinafter 1958 Lisbon Agreement].

4 See infra Section 3. 5 Id.

6 Even though GI registries are not necessary to implement sui generis GI protection, these registries are seen today as formal tools to catalog existing GIs and promote awareness among producers and consumers. This point is elaborated, in particular, in the chapter authored by Naazima Kamardeen on Sri Lanka, in this volume.

7 Irene Calboli, Of Markets, Culture, and Terroir: The Unique Economic and Culture-Related Benefits of Geographical Indications of Origin, in International Intellectual Property: A Handbook of Contemporary Research (Daniel J. Gervais ed., 2015) [hereinafter Calboli, The Benefits of GIs]; Tomer Broude, Taking "Trade and Culture" Seriously: Geographical Indications and Cultural Protection in WTO Law, 26 U. PA. J. INT'L. Econ. L. $623,656-57,674-79(2005)$. 
Section 4 tackles one of the most problematic aspects of the GI debate, namely the progressive loosening of the territorial linkage between GI products and GI regions in the definition of "geographical indications." This section supports the point that, although this territorial linkage has never been an absolute linkage since the first appearance of national laws regulating the use of geographical names, the current trend seems to privilege a considerably looser definition of GIs with respect to the actual geographical origin of the products, their ingredients, and manufacturing process. Hence, the traditional basis for granting exclusive rights on GIs is precisely the territorial linkage between the GI products and the regions - the deep connection between the products and the land, the terroir as it is defined in the French tradition. ${ }^{8}$ In particular, Section 4 specifically recounts that, in 1958 , the text of the Lisbon Agreement ${ }^{9}$ defined "appellations of origin" as signs identifying products "exclusively or essentially" originating from a certain geographical region. This definition was weakened with the adoption of the Agreement on TradeRelated Aspects of Intellectual Property Rights (TRIPS) in 1994, which defines GIs as "indications which identify a good as originating in the territory ... where a given quality, reputation or other characteristic of the good is essentially [no longer exclusively] attributable to its geographical origin." ${ }^{\circ}$ The TRIPS definition finds its origin in the language of the EU Regulations on GIs that were adopted in 1992. ${ }^{11}$ In 2015, the trend of loosening the territorial linkage between the products' name and their actual origin was confirmed in the revision of the Lisbon Agreement finalized in Geneva (Geneva Act of the Lisbon Agreement), as the Geneva Act adopted a definition of GIs (in addition to "appellations of origin") that is identical to the definition in TRIPS. ${ }^{12}$

Naturally, granting exclusive rights to the name of products' locations facilitates the marketing of the products with famous geographical names in the global market - i.e., Champagne sparkling wine, Parmigiano Reggiano hard table cheese, Darjeeling tea, Kintamani coffee, or Kampot pepper. Yet, should this exclusivity be justified when the products do not entirely originate from the regions? Section 5 builds upon Section 4, and argues that when GIs do not identify products that are entirely local, GIs no longer fulfill the function for which they are legally protected - offering accurate information about products' geographical origin to consumers and incentivizing local development. Instead, GIs become marketing tools to sell GI products with

8 Irene Calboli, In Territorio Veritas: Bringing Geographical Coherence in the Definition of Geographical Indications of Origin under TRIPS, 6(1) WIPO J. 57 (2014) [hereinafter Calboli, In Territorio Veritas].

91958 Lisbon Agreement, supra note 3, art. 2(1). $10 \quad$ TRIPS, supra note 1, art. 22(1).

${ }^{11}$ See infra Section 4. ${ }^{12}$ Geneva Act, supra note 3, art. 2(1)(i). 
a competitive advantage - the GI name - on the international market. In this respect, GIs become tools that capitalize on the association between the names and the geographical locations even when this association is based simply on an historical reputation rather than on the accurate geographical origin of the products. To remedy this potential distortion, or misuse of GIs, Section 5 repeats a point that I made in my previous scholarships. In particular, this Section argues that GI protection should be limited only to the products that are entirely made in the GI-denominated regions. ${ }^{13}$ Certainly, (re)creating the normative framework to implement such stricter interpretation of GIs in practice is a highly complex task that may require amending the current definition of GIs in TRIPS - which today protects products' "reputation" as much as the products' actual "geographical origin." Still, while recognizing the challenges of amending the definition in TRIPS, this section also proposes a more workable alternative, which could restore "geographical accuracy" under the current international framework for GI protection. In particular, this section suggests that GI producers disclose directly in the GI specification, as well as on the packaging and the advertising materials related to the products, the origin of all the ingredients, raw materials, and manufacturing steps of the products that do not originate from the GIdenominated regions. To this extent, this section turns to the language of Article 22(2) of TRIPS, which already prohibits the use of GIs to mislead consumers as to the origin of the products, and this provision should also apply to GI producers. ${ }^{14}$ To date, this provision has been interpreted primarily as prohibiting competitors from using GI names misleadingly. Yet, the provision could (and should) apply also to GI producers and be interpreted as requiring that GI producers disclose the actual geographical origin of the entirety of the ingredients and manufacturing steps of products. This section concludes that this interpretation of Article 22(2) would benefit not only consumers but also the producers of raw materials and product ingredients, whose localities would be directly recognized in the global marketplace and production chain. ${ }^{15}$ This

13 See Calboli, In Territorio Veritas, supra note 8, at 63-66.

14 TRIPS, supra note 1, art. 22(2).

15 This conclusion is the result of an insightful conversation with Ms. Natalie Corthésy, Ph.D. candidate at Queen Mary University in London and lecturer at the University of West Indies at Mona, in December 2015. Ms. Corthésy's research focuses on the intellectual property protection of countries' names. She already supported and suggested a similar conclusion. Our conversation focused, in particular, on Jamaica, and the rights of Jamaican producers in being recognized for their agricultural products in the international market. I am grateful to Ms. Corthésy for highlighting the problems that developing countries' farmers face and the lack of academic discussion on this issue so far. 
observation is of considerable relevance for developing countries, including in Asia-Pacific, as many products from these countries, including many GI products, are raw materials and agricultural products. These products are often sold to and used by foreign producers for their finished products, and rarely acknowledged in the packaging or advertising of the finished products.

2 THE GLOBAL, AND FRAGMENTED, DISCUSSION

ON GEOGRAPHICAL INDICATIONS: FROM FRANCE

TO EUROPE, TO THE WORLD

The discussion over GIs generally brings about images of European wines, beers, and cheeses, and with it the decade-long controversy over the names of these products between Europeans and New World producers, primarily producers of European immigrant origins. As other scholars and I have recounted in detail before, this controversy sees, on the one side, the struggle of the Europeans to prevent the New World from copying the geographical names of EU products ${ }^{16}$ - primarily wines and cheeses - based on the argument that the New World free rides on these names and generally produces subpar replicas compared to the original products. In the New World, this argument is met, on the other side, with fierce resistance and the counterargument that European producers are trying to monopolize names that have been used as generic terms for decades, if not centuries, in the New World by immigrants coming from Europe. ${ }^{17}$ These two images certainly embody sharply different points of view over the GI debate. Yet, they also shed an important light over the historical origin of the GI controversy - one that is tackled, from different angles, by the contributions in this volume: namely, these images show how discussions about GIs, and the resulting controversy, were born and have long been dominated by Western interests, literally by

16 See, e.g., the contributions in Dev Gangjee, Research Handbook in Intellectual Property and Geographical Indications (2016); see also the special issue of the International Review of Intellectual Property and Competition Law, 46(7) INT'L Rev. Intell. Prop. \& Competition L. (2015).

17 This position is well summarized in the steady opposition to GIs by the representatives of the Consortium for Common Food Names in the United States. See, e.g., Threats to Common Food Names More Widespread in EU Trade Deals and Other Geographical Indications Policies, Consortium for Common Food Names (March 19, 2015), www .commonfoodnames.com/threats-to-common-food-names-more-widespread-in-eu-trade-deals -and-other-geographical-indications-policies/ (stating the actions taken in several countries to protect common food names such as "parmesan," "feta," and "bologna") [hereinafter Consortium for Common Food Names]. 
a "wine and cheese war" between the Old and New Worlds. ${ }^{18}$ Western interests were clearly at the basis, and at the negotiating table, when the GI provisions in TRIPS were discussed and finalized in the early 1990s, even as the EU was the main proponent of GI protection and New World Western countries were the main opponents. Hence, despite the lack of overall agreement on the issue, both worlds agree on enhanced protection for wines and spirits ${ }^{19}$ - since both (Western) worlds had, and have, important interests in wines and spirits, as the main producers and exporters of these products. ${ }^{20}$ To the contrary, both worlds could not find a common solution with respect to the protection of the names for cheeses primarily due to the resistance of national dairy industries. Several decades after the conclusion of TRIPS, the "cheese war" between Old and New Worlds still rages on.

In the past decades, however, discussions about GIs have expanded beyond the West and reached the attention of other continents and developing countries. Notably, many countries in Asia, Africa, Central America, and South America have expressed interest in GI protection and, as a result, have implemented or are considering implementing specific provisions to protect GIs, including registration-based sui generis systems. ${ }^{21}$ In this respect, it should be noted that several famous GI-denominated products come today from non-Western countries - Darjeeling tea, Ceylon tea, Kampot pepper, Kobe beef, and Blue Mountain coffee are just a few examples of famous non-Western GI products. Contributors to this volume address in detail several of the national initiatives to protect GIs, particularly with respect to the Asia-Pacific region, and elaborate on the legislative history, and where possible the practical application, of these laws. Additional evidence of the increasing interests by non-Western countries in the GI debate is shown by the fact that discussions over GI protection are no longer just about "wine and cheese" or agricultural and food-related products - the latter also part of the GI agenda of Western countries.

18 To date, the "wine" part of this war has been largely resolved with ad hoc wine agreements between Western countries. See Agreement Between the European Community and the United States of America on Trade in Wine, E.C.-U.S., March 10, 2006, 2006 O.J. (L 87) 2 (EC), http://ttb.gov/agreements/us-eu-wine-agreement.pdf. The EU has concluded similar "Wine Agreements," inter alia, with Canada, Australia, and New Zealand. See Irene Calboli, Time to Say Local Cheese and Smile at Geographical Indications? International Trade and Local Development in the United States, 53 Hous. L. Rev. 373, 396-97 (2015) [hereinafter Calboli, Say Local Cheese].

19 TRIPS, supra note 1, art. 23. ${ }^{20}$ Calboli, Say Local Cheese, supra note 18, at 384.

${ }^{21}$ An updated list of national laws on GIs can be found in the database of WIPO. See WIPO Lex, www.wipo.int/wipolex/en/ (last visited August 22, 2016). 
Instead, discussions on GI protection now encompass proposals for expanding protection beyond agricultural products, foodstuffs, wines, and spirits in those countries that still limit protection to these products. ${ }^{22}$ Several countries in Asia-Pacific, for example, have long offered protection as GIs to handicrafts and artisanal products beyond agricultural products and food stuff, and have promoted the expansion of protectable subject matter to encompass these products internationally. ${ }^{23}$ Along the same lines, many non-Western pro-GI countries are promoting, along with Western pro-GI countries such as the EU, the adoption of the higher level of protection currently provided by TRIPS to wines and spirits for all GIs, again because this protection may better suit their national interests in international trade by offering the possibility to protect the names of their products also in the foreign countries where the products are exported and sold to. ${ }^{24}$

Still, even though discussions about GIs - more precisely discussions for and against GI protection - have certainly gone global today, it is important to remember that the modern system of GI protection originates from Europe and, more specifically, from the French laws protecting appellations of origin in the early twentieth century. ${ }^{25}$ Remembering this fact is relevant both to better understand the development of the international movements supporting GI protection and to identify solutions to limiting a possibly excessive expansion of GI protection beyond the economic and normative reasons that were originally at the basis of this protection.

In particular, the origin of GI protection can be traced back to the attempts to prevent fraud in the marketplace for wines in France following the dramatic destruction of French vineyards by a pandemic of phylloxera in the late 1800 s. Due to the pest, the production of French wine considerably diminished, ${ }^{26}$ and this led to widespread counterfeits and adulterated products. ${ }^{27}$ To counter this, France enacted a wine labeling law in 1905 prohibiting the misuse of wine names. ${ }^{28}$ This law was revised in

22 See discussion infra Section 3.

23 See, e.g., Delphine Marie-Vivien, A Comparative Analysis of GIs for Handicrafts: The Link to Origin in Culture as Well as Nature? in Research Handbook in Intellectual Property and Geographical Indications 292 (Dev Gangjee ed., 2016).

24 Id.

25 For one of the most detailed reconstructions of the history and development of GI protection, see Dev Gangjee, Relocating the Law of Geographical Indications 93-96 (2012) [hereinafter Gangjee, Relocating GIs]. Id. at 93-94. $\quad 27$ Id. at 94-95.

28 Loi du 1er Août 1905 sur les Fraudes et Falsífications en Matière des Produits ou de Services, Journal Officiel de la République Française [J.O.] [Official Gazette of France], August 5, 1905, p. 4813 . 
$1919,{ }^{29}$ and later in $1935 .{ }^{30}$ Still, the adoption of the French laws in the early twentieth century was prompted primarily by the necessity to prevent unfair competition in the marketplace by unrelated parties using geographical names inaccurately while also securing the accuracy of the information about products' geographical origin for consumers.

To justify the protection of geographical names, however, the French laws enshrined into the normative framework of protection the notion that location, and more precisely the terroir - a deep connection between the products and the land, as mentioned in the Introduction - where the vine was grown and the wines were made, was a "key ingredient in differentiating between wines by indicating a distinct origin." ${ }^{11}$ This notion represented a considerable step forward in explicitly protecting "geographical origin" from the previously existing laws on unfair competition and, above all, the protection granted to "indications of origin" in the 1883 Paris Convention for the Protection of Industrial Property. ${ }^{32}$ Since then, the notion of terroir has been at the heart of the policy justifications for protecting GIs, including the basis of the argument that GIs are incentive for local and rural development due to the fact that they promote local products. To be precise, the 1891 Madrid Agreement for the Repression of False and Deceptive Indications of Source on Goods (the Madrid Agreement), ${ }^{33}$ which predated the French Law of 1905 by a few years, already included a similar notion - the protection of "regional appellations concerning the source of the products of the vine." ${ }^{34}$ Yet, French negotiators certainly influenced the language of the agreement. In 1958 , the notion of terroir was then confirmed in the Lisbon Agreement, whose imprint from the French laws also cannot be overstated. Certainly the most comprehensive system of protection for appellations of origin adopted at the international level, the Lisbon Agreement also included

29 Loi du 6 Mai 1919 Relative à la Protection des Appelations d'Origine, Journal Officiel DE la République Française [J.O.] [Official Gazette of France], May 8, 1919, p. 4726.

30 Décret-loi du 30 Juillet 1935 Relatif à la Défense du Marché du Vins et au Régime Economique de l'alcool, Journal Officiel de la République Française [J.O.] [OfFicial GaZette of France], July 31, 1935, p. 8314 (creating a system based on controlled appellations of origin).

31 Gangjee, Relocating GIs, supra note 25, at 83.

32 Paris Convention for the Protection of Industrial Property, March 20, 1883, as revised July 14, 1967, 21 U.S.T. 1583, 828 U.N.T.S. 305, arts. 10(1) and 1obis [hereinafter Paris Convention], forbidding "false, fictitious, or deceptive trade names," and the use of any misleading indications (but not specifically geographical indications).

33 Madrid Agreement for the Repression of False and Deceptive Indications of Source on Goods, April 14, 1891, 828 U.N.T.S. 163 [hereinafter Madrid Agreement].

34 Madrid Agreement, supra note 33, art. 2. 
a system of international registration. However, both the Lisbon Agreement and the Madrid Agreement had few signatories and the majority were countries from Europe. ${ }^{35}$ In May 2015, a revised text of the Lisbon Agreement was adopted after a Diplomatic Conference held in Geneva. Supporters of the Geneva Act of the Lisbon Agreement hoped that the new agreement may facilitate a membership increase. ${ }^{36}$ To date, for example, several countries in Asia-Pacific are evaluating the feasibility of joining the revised Lisbon Agreement and the international registration system. Still, the Geneva Act was adopted amidst many controversies and it may not achieve the success hoped for by its proponents.

Ultimately it was only in 1994, with the adoption of TRIPS, that GIs really entered the international stage on a full scale since all WTO Members had to include a minimum-level GI protection in their national laws as part of the obligations established by TRIPS. ${ }^{37}$ The same obligation applied to the countries that joined the WTO after 1994, many of which were countries from the Asia-Pacific region..$^{3}$ Still, non-Western countries were, at large, not active parts in negotiating these provisions, even though several of these countries participated in subsequent negotiations related to the advancement of TRIPS' built-in GI agenda. ${ }^{39}$ In particular, TRIPS established a double system of protection: a "floor level" of protection for all GIs against misleading and unfair competition-based uses of GIs; ${ }^{40}$ and an enhanced level of protection for GIs identifying wines and spirits against usurpation of the GI names, including when "the true origin of the goods is indicated or the $[\mathrm{GI}]$ is used in translation or accompanied by expression such as 'kind', 'type', 'style', 'imitation', or the like."41 TRIPS also established several

35 As of March 2017, only twenty-eight States are contracting parties to the 1958 Lisbon Agreement, and twenty-seven States are signatories of the 1967 Stockholm Revisions. See Contracting Parties, Madrid Agreement, World Intell. Prop. Org., www.wipo.int/treaties/ en/ShowResults.jsp?lang=en\&treaty_id=3. Only thirty-six States are contracting parties of the Madrid Agreement. See Contracting Parties, Lisbon Agreement and Contracting Parties, Stockholm Act, World Intell. Prop. Org., www.wipo.int/treaties/en/registration/lisbon/.

${ }^{6}$ As of March 2017, only fifteen States have signed the Geneva Act. See Contracting Parties, Geneva Act, World Intell. Prop. Org., www.wipo.int/treaties/en/registration/lisbon/.

37 TRIPS, supra note 1, arts. 22-24.

$3^{8}$ For the alphabetical list of the countries that are members of the WTO, which also indicates the date in which the countries joined the WTO, see Members and Observers, World Trade OrG., www.wto.org/english/thewto_e/whatis_e/tif_e/org6_e.htm.

39 For a background to the current debate at the WTO, and the respective proposal by various groups of countries, see TRIPS: Geographical Indications, Background and the Current Situation, World Trade Org., www.wto.org/english/tratop_e/trips_e/gi_background_e .htm\#wines_spirits.

$4^{\circ}$ TRIPS, supra note 1, art. 22(2). $4^{41}$ Id. art. 23. 
limitations to GI protection as a result of the requests of anti-GI advocates. These include provisions on generic terms and the possibility of "grandfathering" existing rights for trademarks that were in use or had been registered in good faith before the date of the implementation of TRIPS in the WTO Member States where the mark was registered, or before the GI was protected in its country of origin. ${ }^{42}$

Nevertheless, the GI provisions in TRIPS did not fully satisfy the requests of the pro-GI countries, which managed to include into TRIPS the commitment to continue the negotiation - in the form of a built-in agenda mandating further negotiations on GIs. ${ }^{43}$ In particular, TRIPS binds WTO Members to hold future negotiations in order to (a) discuss the creation of a multilateral system of notification and registration of GIs (similar to the one already in force under the Lisbon Agreement) for wines and spirits ${ }^{44}$ and (b) "to enter into negotiations aimed at increasing the protection of individual geographical indications [to the level of GIs for wines and spirits]." 45 Because of the delay in pursuing these negotiations - due again to the opposition of anti-GI countries - GI protection was also included in the agenda for discussion in the Doha "Development" Round of WTO negotiations in 2001. ${ }^{46}$ The Doha version of the WTO GI agenda included again the creation of a multilateral register, no longer just for wines and spirits, but for all GIs, and the possibility of extending the higher level of protection provided to wines and spirits to all GIs. ${ }^{47}$ However, no agreement on any of these issues could be reached when WTO Members met in 2003 in Cancun, Mexico. ${ }^{4}$ As a result, multilateral negotiations on GIs have been stalled ever since, and more than a decade after the meeting

42 TRIPS, supra note 1, art. 24(4)-(5). The multinational controversies over several names such as Feta, Fontina, Asiago, and Parmesan as well as the litigation for the rights to the GI (or mark) "Budweiser" across several countries are some of the most famous examples of potential national divergences, and in turn (legal) conflict, regarding the relationship between GIs and, respectively, generic names and registered marks. See Consortium for Common Food Names, supra note 17; Christopher Heath, The Budweiser Cases: A Brewing Conflict, in Landmark Intellectual Property Cases and Their Legacy 181 (Christopher Heath \& Anselm Kamperman Sanders eds., 2011).

43 TRIPS, supra note 1, arts. 23(4), 24(1). $44 \quad$ Id. art. 23(4). $\quad 45 \quad$ Id. art. 24(1).

$4^{6}$ See Doha Declaration, supra note 1. For a detailed analysis of the Doha Declaration, see TRIPs: Issues, Geographical Indications, WOrLd Trade ORG., http://wto.org/english/tra top_e/trips_e/gi_e.htm (last visited August 22, 2016).

47 See Doha Declaration, supra note 1, 18.

$4^{8}$ For more details about the WTO negotiations in Cancun, see TRIPS: Geographical Indications, Background and the Current Situation, World Trade Org., www.wto.org/e nglish/tratop_e/trips_e/gi_background_e.htm (last visited August 22, 2016). 
in Cancun and two decades since the adoption of TRIPS, there is no sign that WTO countries may restart negotiations on the TRIPS' built-in GI agenda any time soon. ${ }^{49}$

Because of this impasse, discussions about GIs have continued primarily as part of FTA negotiations in recent years. Several of these FTAs, and the resulting "FTA maze," are addressed at length in this volume, from the perspectives of both pro-GI and GI-skeptic countries. In a nutshell, pro-GI countries, led by the $\mathrm{EU}$, seem to have been particularly successful in advancing their GI protection agenda as part of the FTA strategy. For example, the EU has negotiated the protection of a long list of EU GIs, including the "claw back" of several terms that are protected as GIs in the EU and were considered generic terms in the jurisdictions of several negotiating parties, in the EU-Canada Comprehensive Trade Agreement, ${ }^{\circ}$ and in the FTAs concluded with Korea, Vietnam, and several South American countries. ${ }^{51}$ To date, EU negotiators are continuing to press the EU GI agenda in trade talks with, inter alia, India, Japan, Malaysia, Australia, New Zealand, and the United States..$^{52}$ The EU is also discussing the extension of its previous stand-alone agreement on GIs with China, through which both the EU and China had registered ten GIs from the other parties in their national, or regional for the EU, jurisdictions. ${ }^{53}$ Considering the importance of China, and Asia, as the export destination for EU products, these results are certainly good news for the EU. To counter the EU strategy, GI-skeptic countries have also engaged in trade negotiations, including GI provisions. This has been the case primarily with the Trans-Pacific Partnership (TPP), which was

49 See World Trade Organization, Article 27.3b, Traditional Knowledge, Biodiversity, WTO Doc. TN/C/W/61 (April 21, 2011), www.wto.org/english/tratop_e/trips_e/art27_3b_e.htm.

Status of Play - Delegations continued to voice the divergent views that have characterized this debate, with no convergence evident on the specific question of extension of Article 23 coverage: some Members continued to argue for extension of Article 23 protection to all products; others maintained that this was undesirable and created unreasonable burdens.

Id. at 4 .

50 See Comprehensive Trade and Economic Agreement, Can.-EU, Consolidated CETA Text, ch. 22, art. 7, Intellectual Property, September 26, 2014, http://trade.ec.europa.eu/doclib/docs/ 2014/september/tradoc_152806.pdf [hereinafter CETA, Intellectual Property Chapter]. See Calboli, Say Local Cheese, supra note 18, at 408-18 (discussing the EU's strategy as part of CETA and suggesting a compromising solution for the TTIP negotiations).

${ }^{51}$ For details on the FTAs concluded by the EU and other countries, or currently under negotiation, see European Commission's Trade Policy Portal, Eur. Comm'n, http://ec .europa.eu/trade/policy/accessing-markets/intellectual-property/geographical-indications/ (last visited August 22, 2016).

52 Id

53 See Geographical Indications (GI), EU-China Trade Project (II), www.euctp.org/index .php/en/agriculture-food-safety/geographical-indications-gi.html (last visited August 22, 2016). 
finalized in 2015, and includes provisions related to "generic terms" and registered marks that may be protected as GIs in other countries. ${ }^{54}$ Still, because of the diverging interests of various TPP members, the final draft of the TPP leaves signatories free to negotiate different provisions in other FTAs, subject only to minimum requirements $5^{55}$ - again a partial victory for pro-GI advocates. Moreover, the United States officially withdrew from the TPP in January 2017, and the agreement may never be ratified by the remaining parties. ${ }^{56}$

\section{THE POTENTIAL BENEFITS, PROMISES, AND PROBLEMS OF GEOGRAPHICAL INDICATIONS FOR ECONOMIC AND SOCIAL DEVELOPMENT}

As indicated in Section 2, besides being one of the most relevant topics of discussion in international trade today, the benefits derived by adopting a national system of GI protection have been discussed also at the national level in a growing number of countries. In particular, GI-related legislations have recently been adopted or updated in several countries, including in AsiaPacific, as detailed by the chapters in this volume. Notably, new or updated laws have been recently adopted, inter alia, in Japan, ${ }^{57}$ Bangladesh, ${ }^{8}$ Singapore, ${ }^{59}$ Indonesia, ${ }^{60}$ and Cambodia. ${ }^{61}$ In other countries, such as Sri

54 See Trans-Pacific Partnership Agreement, ch. 18, arts. 18.30-36 Intellectual Property, October 5, 2015, https://ustr.gov/sites/default/files/TPP-Final-Text-Intellectual-Property .pdf [hereinafter TPP]. When the TPP was finalized, the TPP members were Australia, Brunei Darussalam, Canada, Chile, Japan, Malaysia, Mexico, New Zealand, Peru, Singapore, the United States, and Vietnam. But the United States withdrew from the TPP in early 2017. See infra n.56.

55 Id. art. 18.36. Several TPP members - Vietnam, Malaysia, and Singapore - have concluded, or are discussing, FTAs with the EU.

56 See Office of the United States Trade Representative (USTR), The United States Officially Withdraws from the Transpacific-Partnership, https://ustr.gov/about-us/policy-offices/pressoffice/press-releases/2017/january/US-Withdraws-From-TPP. (last visited i February 2017).

57 Tokutei Norin Suisan Butsu to no Meisho no Hogo ni Kansuru Horitsu [Act for the Protection of the Names of Designated Agricultural, Forestry and Fishery Products and Foodstuffs], June 25, 2014, available at, www.maff.go.jp/j/shokusan/gi_act/outline/pdf/do c4.pdf. (last visited August 22, 2016).

$5^{8}$ The Geographical Indication (Registration and Protection) Act of 2013 (Bangl.).

59 Geographical Indications Act, No. 19 of 2014 (Sing.), not yet in force. When this Act enters into force, it will replace the Geographical Indications Act (Cap 117B, 1999 rev edn.) (Sing.).

6o See Law No. 20 of October 27, 2016, concerning Trade Marks and Geographical Indications amending Law No. 15 of 2001 concerning Trade Marks (Indonesia).

61 The Law on Geographical Indications of Goods ("GI Law") of Cambodia entered into force on January 20, 2014. See Protected Geographical Indications in Cambodia, Agence Francaise DE Developpement, www.afd.fr/webdav/shared/PORTAILS/PAYS/CAMBODGE_2/PDF/ Brochure\%20GI\%20-\%20Cambodia\%2o-\%2oEN.pdf (last visited August 22, 2016). 
Lanka, ${ }^{62}$ Australia, ${ }_{3}$ and New Zealand, ${ }^{64}$ among others, legislative reforms about the current status of GI protection are pending or being discussed. In this respect, it is important to note that these reforms are also taking place in countries that have traditionally been skeptical of GI protection, such as Australia, which is currently debating a possible extension of GI protection for wines to other agricultural products. ${ }^{65} \mathrm{~A}$ similar discussion may soon start in New Zealand, a country that is currently considering a bill to implement more detailed requirements and clarification for the current level of GI protection to wines. As mentioned earlier, the growing participation of Asia and nonWestern countries in discussions on GIs also brought more attention to the request of expanding GI protection to nonagricultural products, namely handicrafts and artisanal goods, such as wood-carved and pottery products, textiles, and so forth. Developing countries are large producers of these products and seek their protection not only at the national level but also internationally. For example, pressure from developing countries (in exchange of protection for EU GIs in their jurisdictions) is certainly part of the reasons why the $\mathrm{EU}$ is now considering expanding GI protection beyond agriculture-based products, ${ }^{66}$ and the proposal for a new Regulation in this respect has already received the unanimous approval of the EU Parliament. ${ }^{67}$ No.9 of 2003, \&30 (Sri Lanka).

64

65

Fair Trading Act of 1986 (N. Z.).

Intellectual Property Act, No. 36 of 2003, $\$ 160$ (Sri Lanka); Consumer Affairs Authority Act,

Wine Australia Corporation Act of 1980; Australian Grape and Wine Authority Act of 2013.

See William van Caenegem, Jen A. Cleary \& Peter Drahos, Provenance of Australian Food Products: Is There a Place for Geographical Indications? (2015), available at https://rirdc.infoservices.com.au/items/15-o6o; William Van Caenegem, Jen A. Cleary, \& Peter Drahos, Pride and Profit: Geographical Indications as Regional Development Tools in Australia, 16 J. Econ. \& Soc. POL'Y (2014), available at http://epubs .scu.edu.au/jesp/voli6/issi/5/.

In 2015, the European Commission published a report evaluating the opportunity to extend GI protection for nonagricultural products. See Results of the Public Consultation and Public Conference on Making the Most Out of Europe's Traditional Know-How: A Possible Extension of Geographical Indication Protection of the European Union to NonAgricultural Products, at 36-37, COM (2014) 469 final (January 20, 2015), http://ec.europa .eu/docsroom/documents/10565/attachments/1/translations/en/renditions/pdf. This report followed a study commissioned by the EU Commission. See Insight Consulting et al., Study on Geographical Indications Protection for Non-Agricultural Products in the Internal Market (2013), http://ec.europa.eu/internal_market/indprop/docs/geo-indications/130322_ geo-indications-non-agri-study_en.pdf.

67 On September 22, 2015, the European Parliament considered the protection of nonagricultural GIs and called "on the Commission to propose without delay a legislative proposal with the aim of establishing a single European system of protection of geographical indications for non-agricultural products." Comm. on Legal Affairs, Report on the 
Certainly, the rise in attention to GIs is again, at least with respect to some countries, the direct effect of FTA negotiations, particularly with the EU. This is the case, for example, of Singapore, a country with no national GIs, which has updated the existing law and adopted a registration-based system of GI protection as part of the obligations undertaken under the EUSingapore FTA. ${ }^{68}$ Other countries, however, already had comprehensive national GI regulations well before negotiating FTAs - this is the case of Vietnam, for instance, a country with a long-standing tradition of GI protection before the EU-Vietnam FTA. ${ }^{69}$ Still, several of the countries, in Asia-Pacific (and elsewhere), that decided to implement a sui generis system of protection, including a registration system, may have done this under the indirect influence from the $\mathrm{EU}$, because of previous colonial ties, or in order to imitate the EU system as a proven successful system in this area when they had to implement the minimum standards of protection mandated under TRIPS. This may be the case of countries such as Bangladesh, Cambodia, China, India, Indonesia, and Thailand among others. All these countries have a registration-based system for GI protection today. In certain instances, several countries in Asia-Pacific seem also to have been influenced by successful experiences of neighboring countries in this respect. For example, it cannot be excluded that, once India implemented a system of GI protection, this triggered discussions about adopting a similar protection in neighboring countries. ${ }^{70}$ Presently, several of the member countries of the Association of South-East Asian Nations (ASEAN) are also stepping up their GI protection based both on a variety of FTA negotiations in the region and the example of successful GI experiences, such as those in Thailand and Vietnam.

In general, this renewed attention to GIs is driven primarily by the belief (or the hope) that GI protection can, or at least may, benefit the national

Possible Extension of Geographical Indication Protection of the European Union to NonAgricultural Products, EU Doc. A8-0259/2015, at 6/26, 93 (2015), www.europarl.europa.eu/ sides/getDoc.do?pubRef=-//EP//NONSGML+REPORT+A8-2015-0259+o+DOC+PDF+ Vo//EN.

68 See Geographical Indications Act, No. 19 of 2014 (Sing.). See also EU-Singapore Free Trade Agreement, EU-Sing., September 20, 2013, http://ec.europa.eu/trade/policy/countries-andregions/countries/singapore/.

69 Civil Code of Vietnam (1995), art. 786 (Vietnam). In 2015, the EU and Vietnam concluded the EU-Vietnam FTA. See EU-Vietnam Free Trade Agreement: Agreed Text as of January 2016, Eur. Comm'n, February 1, 2016, http://trade.ec.europa.eu/doclib/press/index.cfm?id=1437.

$7 \circ$ This is the case of Sri Lanka and Bangladesh, for example, following the adoption of GI protection in India. See the chapters by Naazima Kamardeen and Mahua Zauhr in this volume. 
economies of the countries adopting these laws. Several of the contributions to this volume discuss the potential benefits, but also the possible pitfalls, of GI protection in several countries in Asia-Pacific.

In particular, as I have recounted before, one of the staple arguments in support of GI protection - in Europe, Asia, and worldwide - is precisely the proposition that granting exclusive rights on geographical names associated to products coming from certain regions would translate into incentivizing and promoting local and rural development in those regions. ${ }^{71}$ This argument rests on the consideration that groups of regional producers would be motivated to start investing, or continue to invest, in the production of certain types of products that traditionally originate from a given region, if they can secure exclusive rights on the geographical names of that region. This is because, in the view of the producers, obtaining exclusive rights on the GIs would guarantee the ability to capture the full profit for the quality and characteristics of the products, including the added value that the GIs could give to the products - e.g., the fact that consumers locally, nationally, or internationally may be willing to pay a premium price for sparkling wine from Champagne, tea from Darjeeling, and pepper from Kampot.

Hence, in order to secure these exclusive rights, collectivities of regional producers should work together to identify a common process that defines the uniqueness of the GI products, and submit the products' specification with the application to register the GI. Producers should also identify quality control bodies, both internal and external, to certify the conforming of the products to the specification. ${ }^{72}$ Once the GI is registered, the collectivity of producers (which generally also remain competitors in the intra GI market) is bound by

${ }^{71}$ See Calboli, The Benefits of GIs, supra note 7, at 447-52 (summarizing the economic arguments in favor of GI protection); see also GangJeE, Relocating GIs, supra note 25, at 183 (noting that GIs are protected due to the possibility to "generate improved incomes and tangible benefits for groups of rural or marginalized groups”). See also, e.g., Sarah Bowen, Embedding Local Places in Global Spaces: Geographical Indications as a Territorial Development Strategy, 75 Rural Soc. 209 (2010); Giovanni Belletti \& Andrea Marescotti, Gi Social and Economic Issues 15 (2006), available at www.origin-food .org/2005/upload/SIN\%20-\%20WP2\%2oFinalReport\%2oDEF.pdf.

72 This is a very important step in the process of GI registration, which traditionally sees the involvement of the state, as a certifying public authority, and the selection of private, yet independent, bodies for quality control. For example, the quality control body for the GI Parmigiano Reggiano is the Organismo di Controllo Qualità Produzioni Regolamentate. See Organismo di Controllo Qualità Produzioni Regolamentate [Organism for Quality Control of Regulated Productions], www.ocqpr.it/ (last visited August 22, 2016). The quality control body for the GI Prosciutto di Parma is Istituto Parma Qualità. See Istituto Parma Qualità [Institute Parma Quality], www.parmaqualita.it/ (last visited August 22, 2016). 
the specification, and this guarantees the consistency of the quality and characteristics that consumers expect to find in all GI-denominated products. ${ }^{73}$

In other words, GIs facilitate not only local development by tying producers to the land, but also producers' cooperation to maintain the quality of the products for the collectivity. Overall, the impact of GI protection on development continues to strengthen when GI-denominated products become established in the marketplace, as GIs incentivize the producers to continue to invest in the quality of the products. ${ }^{74}$ Moreover, since the land is the essential wealth, the heart, upon which the fortune of the GI producers is constructed, GIs also function as incentives for producers to adopt long-term strategies for safeguarding and enhancing the well-being of the land. In particular, GI producers are aware that the long-term health of the land and the resources of the region are crucial for the long-term success of GI products and generally work together to maintain the well-beingness of the region. Besides benefitting GI producers, this can have positive spillover on the region landscapes and in turn several other industries built around the GI products - for example, a variety of service providers, the tourism industry, including eco-tourism, and regional retailer of GI products and the producers of products that can accompany the sale of GI products.

Moreover, whereas GIs permit producers to capture the added value of GI products, GIs also operate as "badges of accountability" for those producers who decide to produce subpar products or simply not respect the requirements listed in the GI specification. In particular, under the current normative framework of GI protection, these producers will be forbidden from using the GI unless they return to producing following the mandated standards. In light of this possibility, the importance of quality control on GI products cannot be overstated. In this respect, several countries in Asia-Pacific have recently implemented or have revamped the systems of quality control

73 For example, all European GIs for agricultural products and food stuff are registered in the online database “DOOR." See DOOR, Denomination Information, Eur. Comm'n, http://ec .europa.eu/agriculture/quality/door/list.html (last visited August 22, 2016). Moreover, the websites of many registered PDOs and PGIs indicate the specifications and quality control related to the products.

74 See Gangjee, Relocating GIs, supra note 25, at 266 ("Since consumers are willing to pay more for such goods, this encourages farmers to invest in making the transition from producing un-differentiated bulk commodities, towards producing higher quality niche products"). See also Michelle Agdomar, Removing the Greek from Feta and Adding Korbel to Champagne: The Paradox of Geographical Indications in International Law, 18 Fordham Intell. Prop. MEDi \& EnT. L.J. 541, 586-87 (2008) (noting that granting property rights through geographical indications allows producers to control the quality of their goods in order to build consumer confidence). 
of GI-denominated products in order to effectively ensure that the products comply with the product specifications. ${ }^{75}$

The second argument in support of GI protection is that GIs provide consumers with relevant information about the GI products. ${ }^{76}$ In particular, from a public policy standpoint, GIs offer to consumers, including retailers purchasing GI-denominated products for resale, information that can reduce the information asymmetries that consumers usually face compared to producers at the time of purchase. In other words, GIs offer additional information about the quality and characteristics of the products, and this offers consumers the possibility to make a better-informed decision about their purchase. ${ }^{77}$ GIs can also offer relevant information about the safety and the health of the products because they offer information about the origin and the practices that go into making the products. ${ }^{7}$ Similarly, GIs can provide information about the impact of the manufacturing and other practices used to produce the GI-denominated products on the environment, and even labor practices, including overall human rights. Again, this set of information could assist consumers in identifying potentially healthier foods for their individual needs, or artifacts made with traditional or environmentally friendly manufacturing techniques for those countries that provide GI protection beyond food-related products. As mentioned earlier, GIs can even reduce possible "contagion effects" due to negative incidents in a given geographical market for a certain type of product. ${ }^{79}$ This was the case, for example, with respect to the scandal of the contaminated "mozzarella di bufala campana," a GIdenominated product from Italy. ${ }^{8 \circ}$ In this case, consumers could use the information provided by the GI to know that they should avoid the products

75 See, e.g., Trong Binh Vu \& Duc Huan Dao, Geographical Indication and Appellation of Origin in Vietnam: Reality, Policy, and Perspective, Institute of Policy and Strategy for Agriculture and Rural Development - MisPa Project (2006), available at www .fao.org/fileadmin/templates/olq/documents/documents/GI\%zoand\%zoAO\%zoin\%zoViet nam.pdf [hereinafter, Binh \& Huan, GI and Appellation of Origin]; see also Chuthaporn Ngokkuken \& Ulrike Grote, Challenges and Opportunities for Protecting Geographical Indications in Thailand, 19 AsIa-PaC. Dev. J. 93 (2012).

76 See Calboli, The Benefits of GIs, supra note 7, at 435; GangjeE, ReLocating GIs, supra note 25 , at 183 (GIs are protected because they "must actually provide useful information to consumers in an established market").

77 Agdomar, supra note 74, at 586-87 (noting that GIs constitute methods of improving asymmetrical information as they signal quality and expertise and enable consumers to distinguish between premium-quality products and low-end products). Id. at 587-88. 79 See Calboli, The Benefits of GIs, supra note 7, at 447-52.

8o See Michael McCarthy \& John Phillips, Italy's Toxic Waste Crisis, the Mafia - and the Scandal of Europe's Mozzarella, The IndePEndent (March 22, 2008), www.independent .co.uk/news/world/europe/italys-toxic-waste-crisis-the-mafia-ndash-and-the-scandal-of-eur opes-mozzarella-799289.html. 
originating in the affected region, while they could safely continue to purchase the generic product "mozzarella di bufala" from other regions.

In addition to the arguments that GI promotes economic development and reduces information asymmetries from consumers, another argument has been brought forward in recent years to justify GI protection. This argument is directly addressed by several contributions in this volume and centers on the proposition that GIs can protect the cultural identity of local and regional communities, which in turn may contribute to promoting cultural diversity. ${ }^{81}$ The growing importance of GIs under the lenses of culture-related concerns finds additional support in two separate conventions that have been recently adopted under the patronage of the United Nation Educational, Scientific and Cultural Organization (UNESCO): the 2003 Convention for the Safeguarding of the Intangible Cultural Heritage ${ }^{82}$ and the 2005 Convention on the Protection and Promotion of the Diversity of Cultural Expressions. ${ }^{83}$ Under the UNESCO framework, GIs seem well suited for the protection of culture-based interests because GI products frequently relate to local and traditional knowledge of the region where the products are made. ${ }^{84}$ Thus, granting exclusive rights to GIs could serve to promote the continuation of traditional manufacturing techniques, which could otherwise succumb to the competition of mass production techniques. Moreover, GIs directly contribute to reinforcing local identities by again promoting the making and selling of local products. As others and I have suggested, this may promote greater product diversity in an economy where products would be otherwise increasingly similar due to the globalization of trade and the de-localization of product manufacturing. ${ }^{85}$

81 In this respect, see Calboli, The Benefits of GIs, supra note 7, at 439; see also, e.g., Toshiyuki Kono, Geographical Indication and Intangible Cultural Heritage, in LE Indicazioni Di Qualità Degli Alimenti 289 (Benedetta Ubertazzi \& Esther Muñiz Espada eds., 2009); Tomer Broude, A Diet Too Far? Intangible Cultural Heritage, Cultural Diversity, and Culinary Practices, in Diversity in Intellectual Property: Identities, Interests, and Intersections 472 (Irene Calboli \& Srividhya Ragavan eds., 2015).

82 Convention for the Safeguarding of the Intangible Cultural Heritage, October 17, 2003, in force April 20, 2006, 2368 U.N.T.S. 1, available at http://unesdoc.unesco.org/images/oo13/oo $1325 / 13254$ oe.pdf.

83 Convention on the Protection and Promotion of the Diversity of Cultural Expressions, October 20, 2005, 2440 U.N.T.S. 346 available at http://en.unesco.org/creativity/sites/creativ ity/files/passeport-conventionzoo5-web2.pdf.

84 See, e.g., Teshager W. Dagne, Harnessing the Development Potential of Geographical Indications for Traditional Knowledge-based Agricultural Products, 5 J. INTELL. Prop. L \& PRAC. 441, 447 (2010).

85 See Calboli, The Benefits of GIs, supra note 7, at 439; Dev Gangjee, Geographical Indications and Cultural Heritage, 4 WIPO J. 92, 99 (2012). 
Hence, as Justin Hughes pointedly observes in this volume, for all their potential benefits for local development and culture, GIs are not a magic recipe for success for local producers. Instead, several of the GIs that have been registered in the $\mathrm{EU}$, and elsewhere, to date, have not brought to their producers more than some modest returns and, at times, the same returns as non-GI products. This has been proven true, in particular, with respect to raw materials and non-processed agricultural products. ${ }^{86}$ As a result, this partially questions the value of GIs for these products. In turn, this raises question about the value of GI protection for developing countries, as many of the GIs registered and protected in these countries are for raw materials and non-processed agricultural products. Moreover, developing countries often lack the infrastructure to enact strict quality control programs, and appropriate marketing of the products. Similarly, foreign enterprises are often deeply involved in the management of GIs in developing countries, which may lead to their business interests prevailing over long-term local (and thus national) development. ${ }^{87}$ This could become problematic for local communities, particularly when foreign businesses push for excessive production and fast-paced growth of the products' quantities. ${ }^{88}$ More generally, the success of any GI products can become a double-edged sword and lead to inconsiderate exploitation of the land and natural resources without proper management of the GIs and a long-term strategic plan for the growth and development of the products. In turn, this could directly and negatively affect the local environment, and overall the sustainability of the production of the GI products themselves. A telling example in AsiaPacific is the case of "Phu Quoc," which was registered as a GI for fish sauces in Vietnam in 2001. After obtaining the GI registration, national (and foreign) producers overproduced without implementing a rigorous system of quality control for the products for several years. This led to unwelcome results for the local environment, and the simultaneous rise of counterfeits. ${ }^{89}$ Only recently, a control body for the Phu Quoc products was established and the body has stepped up in controlling the quality and authenticity of the products.

Areté, Study on Assessing the added Value of PDO/PGI (2013), http://ec.europa.eu/ agriculture/external-studies/2013/added-value-pdo-pgi/exec-sum_en.pdf. See Bowen, supra note 71 . See, e.g. Jennifer Barnette, Geographic Indications as a Tool to Promote Sustainability? Café de Colombia and Tequila Compared, 39 Ecology L. Q. 102 (2012).

89 For a detailed discussion on the "Phu Quoc" registration process, see Binh \& Huan, GI and Appellation of Origin, supra note 75. 


\section{TERROIR WITH LESS TERROIR? THE RISE \\ OF “REPUTATION-BASED” GEOGRAPHICAL INDICATIONS, THE \\ LOOSENING TERRITORIAL LINKAGE, AND RISKS THEREOF}

This section argues that GI protection becomes more questionable when the products do not entirely originate from the GI regions and GI producers use a partially de-localized production model for their products. Unfortunately, despite the claims of "geographical purity" supported by pro-GI advocates, this partially delocalized model of production for GI products seems today to be more the norm than the exception, with the blessing of international law and most national laws on GIs. Hence, when GIs do not identify fully locally made products, GI protection can easily transform in subsidies and thus confirm the concerns that are often expressed by GI skeptics. In essence, as I argued in my previous scholarship, granting exclusive rights when GIs do not identify fully locally made products risks to transform GIs into a marketing tool rather than signs of the accurate geographical origin of the products at issue..$^{90}$ This, in my opinion, seems to run against the very rationale for protecting GIs in the first place - the linkage between the products and the land, in other words the commonly celebrated unique relationship between the products and the terroir.

Certainly, it should be noted that the relationship between the terroir and the products originating from the land has been partially romanticized. In particular, this relationship was never absolute and overly strict, despite the (often conveniently painted) arguments of GI supporters. This was already the case with respect to the first laws on GIs - or, more precisely, their predecessors "indications" and "appellations" of origin - in the legal landscape. Yet, as mentioned in Section 2, starting with the French laws of the early 1900s, and a few years prior with the Madrid Agreement, it is accurate to say that the broad justification for protecting indications of geographical origin was enshrined in the notion that these indications deserved separate protection from other distinctive signs - primarily trademarks - because of the special relationship between the location from which the products originate and the overall characteristics of the products. In 1958, the definition of "appellations of origin" in the Lisbon Agreement codified this notion in Article 2(1), which reads that "appellations of origin" are the "geographical name[s] of a country, region, or locality, which serve to designate a product originating therein, the quality and characteristics of which are due exclusively or essentially to the geographical environment, including natural and human 
factors." ${ }^{11}$ Article 2(2) of the Lisbon Agreement further clarified that " $t$ t]he country of origin is the country whose name, or the country in which is situated the region or locality whose name, constitutes the appellation of origin which has given the product its reputation." ${ }^{2}$

Certainly, despite its strong emphasis on the "geographical environment," the very language of the Lisbon Agreement already reflected some flexibility in the definition of "appellations of origin." Notably, Article 2(1) does not impose an "exclusive" connection between the products and the land, but just an "exclusive or essential" connection. Moreover, the definition in Article 2(1) adds "human factors" to "natural factors" with reference to the "exclusive or essential" elements of the products' quality or characteristics. As supported by prominent scholars, reference to human factors may be seen as evidence to support a system of GI protection focused on localities as the place not only where products are grown but also where the products are made, possible with ingredients and raw materials partially originating from outside the region. Last, but not least, the Lisbon Agreement also refers to the notion of product "reputation," a concept later found in TRIPS, even though the combined reading of Article 2(1) and 2(2) indicates that the use of the wording "reputation" in Lisbon is a narrow one, meaning primarily that protectable appellations of origin are the names of those geographical locations that have given reputation to a certain product coming from those locations. As explained in the remainder of this section, the concept of "reputation" has later emerged as an (almost) independent justification for protecting GIs today - a tendency that Dev Gangjee explores in this volume based on both a "geography" and "history" approach.

Still, the major loosening of the definition of GIs away from a strict interpretation of the notion of "geographical origin" was the direct result of the adoption of TRIPS in 1994. Notably, Article 22(1) of TRIPS blends the concept of terroir - in its romantic interpretation as absolute relationship between the products and the land - with a much wider concept of "reputation" compared to the concept in the Lisbon Agreement. In particular, Article 22(1) of TRIPS defines GIs as "indications which identify a good as originating in the territory ... or a region or locality in that territory, where a given quality, reputation or other characteristic of the good is essentially attributable to its geographical origin." 93 In other words, the provision in

$9^{1} 195^{8}$ Lisbon Agreement, supra note 3, art. 2(1) (emphasis added). $\quad 9^{2} \quad$ Id. art. 2(2).

93 TRIPS, supra note 1, art. 22(1). The definition in TRIPS was certainly influenced by WIPO's definition of GIs as "sign[s] used on goods that have a specific geographical origin and possess qualities, reputation or characteristics that are essentially attributable to that origin.” World Intellectual Property Organization (WIPO), What is a Geographical Indication? www.wipo .int/geo_indications/en/ (last visited August 22, 2016). 
TRIPS makes of the linkage between products and the land just an "essential" and no longer an "exclusive or essential" element for GI protection. This loosening of "geographical accuracy" in the TRIPS" definition of GIs is exacerbated by the fact that TRIPS includes the notion of "reputation" front and center in the definition of GIs, treating "reputation" as an equally significant element for GI protection as the other characteristics and qualities of the GI-denominated products. In other words, following TRIPS, producers in a given region are able to claim exclusive rights on the geographical names of the region with respect to their products even though the products may be manufactured with ingredients entirely originating from outside the region, simply because the name of the region has, historically, been linked with the products and has given to the products their reputation (most likely because the products were first made, or became famous when they were made, in the region).

As I mentioned in the Introduction, it is a known fact that the language of Article 22(1) of TRIPS was heavily influenced by the language of the existing EU Regulations at the time of the TRIPS negotiations, and that the EU strongly supported this language. Notably, Council Regulation (EEC) No. 2081/92 of July 14, 1992, on the protection of GIs and designations of origin for agricultural products and foodstuffs ${ }^{94}$ protected two different types of GIs: "geographical indications" (PGIs), which were defined as "the name[s] of a region, a specific place or, in exceptional cases, a country, used to describe an agricultural product or a foodstuff" that are "originating in that region, specific place or country" and "which possess a specific quality, reputation or other characteristics attributable to that geographical origin and the production and/or processing and/or preparation of which take place in the defined geographical area"; 95 and "designations of origin" (PDOs), which were defined as "the name[s] of a region ... used to describe an agricultural product or a foodstuff" that are "originating in that region, specific place or country" and "the quality or characteristics of which are essentially or exclusively due to a particular geographical environment with its inherent natural and human factors, and the production, processing and preparation of which take place in the defined geographical area." ${ }^{6}$ For the latter type of GIs, the PDOs, a stronger link with the territory was required under EU law, but that was not the case for PGIs. Moreover, Regulation No. 20181/92 provided that "certain geographical Designations of Origin for Agricultural Products and Foodstuffs, 1992 O.J. (L 208) 1, [hereinafter Regulation 2081/92]. 
designations shall be treated as designations of origin where the raw materials of the products concerned come from a geographical area larger than or different from the processing area." ${ }^{\prime 97}$ Regulation 2081/92 was later amended and replaced, but today's Council Regulation (EC) No. 1151/2012 (Agricultural Products and Foodstuff Regulation) ${ }^{98}$ and Council Regulation (EC) No. 479/2008 (Wine Regulation $)^{99}$ repeat almost verbatim the same definitions for PGIs and PDOs. Council Regulation (EC) No. 119/2008 (Spirits Regulation) only refers to "geographical indications" for spirits. ${ }^{100}$ Despite their differences in the requirements to qualify as PGIs or PDOs, both types of GIs enjoy the same level of (enhanced) protection in the EU.

Besides the influence of the EU Regulations on the definition in TRIPS, in May 2015, a provision blending Article 22(1) of TRIPS and the EU definitions was introduced into the Geneva Act of the Lisbon Agreement, ${ }^{101}$ which amends the definition in Article 2(1) of the Lisbon Agreement. In particular, similar to EU law, the Geneva Act definition now includes two types of GIs, namely "geographical denominations" and "geographical indications." More specifically, Article 2(1) of the Geneva Act defines (i) geographical "denominations" as signs which "designate a good as originating in that geographical area, where the quality or characteristics of the good are due exclusively or essentially to the geographical environment, including natural and human factors, and which has given the good its reputation"; ${ }^{102}$ and (ii) geographical "indications" as signs which "consist of or contain the name of a geographical area, or another indication known as referring to such area, which identifies a good as originating in that geographical area, where a given quality, reputation or other characteristic of the good is essentially attributable to its geographical origin." ${ }^{103}$ In this respect, Article 2(1)(i) of the Geneva Act

97 Id. art. 2(4). The provision put the following conditions: "provided that: the production area of the raw materials is limited; special conditions for the production of the raw materials exist, and there are inspection arrangements to ensure that those conditions are adhered to."

Regulation 1151/2012 of the European Parliament and of the Council of November 21, 2012, on Quality Schemes for Agricultural Products and Foodstuff, 2012 O.J. (L 343) 1, art. 5(1)-(3).

99 Council Regulation 479/2008 of April 29, 2008, on the Common Organization of the Market in Wine, Amending Regulations 1493/1999, 1782/2003, 1290/2005, 3/2008 and Repealing Regulations (EEC) No 2392/86 and 1493/1999, 2008 O.J. (L 148) 1, art. 34(1)(a)-(b). In addition, art. 31(1)(c) includes in the definition of "designation" certain "traditional used names" provided that "(a) designate a wine; (b) refer to a geographical name; (c) meet the requirements referred to in paragraph 1(a)(i) to (iv) [of Article 34(1)(a)]; (d) undergo the [relevant] procedure conferring protection on designations of origin and geographical indications."

100 Regulation 110/2008, of the European Parliament and of the Council of January 15, 2008, on the Definition, Description, Presentation, Labeling and the Protection of Geographical Indications of Spirits Drinks and Repealing Council Regulation (EEC) 1576/89, 2008 O.J. (L 39) 16, art. 15. Geneva Act, supra note 3, art. 2. $\quad{ }^{102} \quad$ Id. art. 2(1)(i). ${ }^{103}$ Id. art. 2(1)(ii). 
merges the language of Article 2(1) and 2(2) of the Lisbon Agreement, adding to the definition of "geographical denomination" (previously "appellations of origin") the wording "which has given the product its reputation." 104 Article 2(1) (ii) repeats the TRIPS and EU definition for "geographical indications," and refers to "reputation" as an element sufficient, per se, for granting exclusive rights on GIs. ${ }^{105}$ Article 2(2) of the Geneva Act then enlarges the scope of the definition even more in Article 2(1) by defining "geographical area" as potentially also "the entire territory of the Contracting Party of Origin [thus a whole country] or a region, locality or place in the Contracting Party of Origin." ${ }^{106}$ This area can now consist also "of a trans-border geographical area, or a part thereof." ${ }^{107}$

In summary, the review of the development of the current definition of GIs directly reflects a far less stringent relationship between GI products and the terroir than the one that is often purported in the GI debate. This review shows, in particular, a progressive loosening of this linkage, at least in terms of the dependence of the products from the physical and natural resources of the GI regions. It also shows the rising importance of the human factors, traditionally a partially less relevant element in the GI debate compared to the physical and natural resources, as a qualifying element per se for claiming exclusive rights on geographical names. More problematically, it empowers national authorities to grant GI rights based simply on the reputational link between products and geographical names. Not surprisingly, the loosening of the strictness of this territorial linkage matches changes in international trade, including trade facilitations and a larger access to raw materials from foreign markets at reduced, or no longer existent, tariff barriers. Under the current system, GI producers could have the best of both worlds - claiming exclusive rights on famous locations that grant a competitive advantage to their products against competitors on the one side, and the possibility of accessing cheaper raw materials in foreign markets, if not cheaper human factor, at least in part, for processed GI products, including handcrafts and artisanal goods. Hence, this system no longer accurately identifies the geographical origin of the GI products nor fulfills the functions that are at the core of GI protection:

\footnotetext{
104 Id. art. 2(1)(i). ${ }^{105}$ Id. art. 2(1)(ii).

106 Id. art. 2(2).

107 Geneva Act, supra note 3, art. 2(2). This option could resolve several ongoing disputes between neighboring countries over the origin of certain products, such as Basmati rice or Emmentaler cheese. See Basmati, Registration No. 4076214 (India); Emmentaler Tradition Switzerland, Registration No. 583659 (S.Z.); Allgäuer Emmentaler, Dossier No. DE/PDO/ 0017/0459 (Germany); Emmental de Savoie, Dossier No. FR/PGI/ o017/o179 (France).
} 
incentivizing local and rural development, and offering accurate information to consumers.

As I mentioned before, the protection of GIs - well-known GIs in particular certainly offers an important legal alternative in a world in which agricultural subsidies, and other trade subsidies, are increasingly scrutinized as barriers to international trade. In this respect, GIs permit producers to continue to secure some "monopoly rent" against competing products in the international market. ${ }^{108}$ Not surprisingly, the loosening of the definitions of GIs has been supported precisely by those nations and stakeholders representing GIintensive countries and industries, such as the EU. Yet, this begs the following question: is this "modern" system of GI protection compatible with the historical objectives of this protection? Moreover, under the current system, the blame and shame for any problems related to products not fully originating from GI-denominated regions may be erroneously passed on to other GI producers, including those who entirely produce their products in the GIdenominated area. Ultimately, as I elaborate in the following section, this modern system of protection could be made compatible with the traditional objectives of GI protection, should GI producers clearly disclose the actual geographical origin of the raw materials, product ingredients, and manufacturing steps that do not originate from the GI region. This is of particular importance to, and thus should interest, developing countries in Asia-Pacific and elsewhere, as these countries are strong producers, and exporters, of (mostly agricultural) raw materials and non-processed products, which are, or could be, used by other countries' producers.

\section{FULL DISCLOSURE REQUIRED: THE CASE FOR A SYSTEM \\ OF PROTECTION BASED ON A MORE FLEXIBLE, BUT STILL ACCURATE, NOTION OF "GEOGRAPHICAL ORIGIN"}

Based on the considerations in Section 4, it is not an exaggeration to state that the system of GI protection that is currently being embraced by TRIPS and other relevant international agreements and national legislations directly favors a flexible notation of "geographical origin," which does not necessarily include the origin of all the ingredients and steps of manufacturing that are used and needed for the production of the GI products. In this respect, criticisms by GI skeptics exposing the inconsistency between this reality and the arguments put forward by GI supporters that GI deserves special

108 See Justin Hughes, Champagne, Feta, and Bourbon: The Spirited Debate About Geographical Indications, 58 Hastings L.J. 299, 345 (2006). 
protection because of the linkage between the products and the terroir are thus well taken. Still, these criticisms should not let us lose sight of the actual and potential benefits that a system of GI protection which is focused on accurate information, can otherwise bring to both consumers and local development. Moreover, we should not forget that the criticisms expressed against GI protection often derive from supporters of an anti-GI agenda, an agenda that frequently aims to protect the national interests of businesses that use (misusing them in the view of this author) foreign GIs to identify their generic national products - frequently adding to the packaging of these products additional misleading elements, such as flags, national symbols, and color schemes reminiscent of the foreign countries from where the GIs originate and that are famous for their GI products.

Ultimately, as the contributions to this volume illustrate from a variety of different angles, as much as GI protection favors a certain set of interests those of localities with strong agricultural or artisanal traditions and the businesses in these localities that grow or manufacture products related to these traditions - the lack of appropriate GI protection favors another set of interests - those of businesses producing similar products to be sold under names that are similar to the existing geographical names even though the products do not share any geographical link with those locations. Disputes over terms like Budweiser, Champagne, or Parma between business interests in different countries are illustrious examples of these conflicting interests. ${ }^{109}$ Accordingly, the arguments put forward by GI skeptics should also be carefully vetted as these arguments may also not offer optimal solutions for consumers and (national and/or local) economic development. For example, in some instances, the use of GI names in unrelated contexts in different countries does indeed derive from decades of usage by immigrant communities, or is due to the fact that the GI terms have indeed become generic terms in those countries. In this case, specific exceptions should be, and generally have been, carved out with legal solutions. Hence, these cases are less frequent than GI skeptics tend to purport. In contrast, in several cases, the inappropriate use of GIs by third parties in foreign countries seems to be done with the specific intent to exploit the association generated by these terms with certain (famous) foreign geographical places in order to create a sense of déjà vu and reassurance in consumers, especially in other jurisdictions where these "GI look-alike" products compete with authentic GI products. This is certainly the case with respect to the names of many cheeses available in the market in New World countries today. 
Still, despite these flaws in the arguments of GI skeptics, a more rigorous interpretation of the notion of "geographical origin," one that better complies with the normative objectives that have been traditionally invoked to justify GI protection, is nevertheless needed to restore legitimacy in the arguments supported by GI advocates in favor of GI protection, especially when these arguments are used to request that other countries agree to adopt additional protection beyond the level currently provided for in TRIPS. As I mentioned earlier and have also argued in my previous scholarship, ${ }^{11}$ in the absence of a considerable "refocus" toward greater geographical accuracy (i.e., toward a system in which GIs effectively convey accurate information about products' geographical origin), GI protection may become nothing more than a monopoly (and more problematically one not limited in time) on geographical names for possibly no other sound reasons than the historical reputation of a certain location. In this case, however, GI protection no longer brings about the benefits that communities had hoped for in terms of local development - as part of the products would be made outside the regions. Likewise, the use of GIs may result in increasing, rather than decreasing, the information asymmetries between producers and consumers as to the actual origin and quality of the products at issue. In other words, from badges of geographical origin and associated characteristics, GIs may become just badges of misleading information to induce consumers to believe that products originate from a region, even though, in practice, the ingredients may originate, at least in part, elsewhere, or simply badges of a reputation that is associated to a location only based on past traditions which no longer exist.

In a previous article, in 2014, ${ }^{111} \mathrm{I}$ argued in support of the adoption of a narrower and more geographically coherent definition of GIs to resolve the risks of geographical inaccuracy, or inconsistency, which may plague the current system of GI protection. This narrower approach, I argued, could be based on limiting the granting of GI protection only to those products that are actually grown in the GI regions, or effectively originate from these regions with respect to the entirety of the ingredients and manufacturing steps necessary to manufacture the finished products. To reach this result, I suggested that one option could be to delete the wording "reputation" from Article 22(1) of TRIPS, and with it the possibility to grant exclusive rights on GIs just based on the "reputation" of the GI products without any additional link to the actual quality and characteristics of these products. Likewise, I suggested the removal

$110 \quad$ Id. at $63-66 . \quad{ }^{111} \quad I d$. 
of the word "essentially" from the definition of GIs in Article 22(1), so that GIs would be defined as "indications which identify a good as originating in the territory of a Member, or a region or locality in that territory, where a given quality, or other characteristic of the good, is attributable to its geographical origin." ${ }^{112}$ Alternatively, I suggested the introduction into TRIPS' definition in Article 22(1) the wording "essentially or exclusively" as in the 1958 version of the Lisbon Agreement. ${ }^{113}$ In my opinion, this language would better reflect a very high level of geographical connection between the products and the GIdenominated areas. Today, in light of the 2015 Geneva Act of the Lisbon Agreement, this proposal should include amending the new definition in the Geneva Act discussed in Section 4, as this definition has been modeled after TRIPS.

However, as I already acknowledged in 2014, amending TRIPS is likely to be an impossible task today, due to the current gridlocking of trade negotiations within the WTO and the collapse of the Doha multilateral agenda. ${ }^{114}$ Moreover, many countries have implemented a definition of GIs similar to TRIPS, thus any amendment of TRIPS should be followed by the amendments of these national laws. This would certainly result in an equally complex, if not again an impossible, task to achieve in practice.

Still, a perhaps less radical but effective proposal for a refocus of the current system of GI protection toward a system based on a stricter territorial linkage and more transparent disclosure of the geographical origin of the products may nonetheless be possible under the current framework. In particular, after further thinking and discussing this issue, I have reached the conclusion that the key for such a solution lies in interpreting the definition of Article 22(1) in light of the provision in Article 22(2) of TRIPS, which forbids any misleading use of a GI and states that "interested parties" are entitled to oppose "(a) the use of any means in the designation or presentation of a good that indicates or suggests that the good in question originates in a geographical area other than the true place of origin in a manner which misleads the public as to the geographical origin of the goods." 115 As noted in Section 2, this provision provides the minimum protection for all GIs against misleading uses. Yet, nothing in the language of the provision seems to indicate that only GI producers can invoke Article 22(2) to oppose the misleading use of GIs by third parties. Instead, the provision clearly applies to all misleading use of a GI. This may include all the cases in which GI producers use a GI to identify products that do not fully originate from the region, should the public believe

${ }_{112}$ Id. ${ }^{113} \quad$ Id. ${ }^{114} \quad$ Id. $\quad{ }^{115} \quad$ TRIPS, supra note 1, art. 22(2). 
that the products entirely originate from the region. In other words, this may include the cases in which GI producers turn to ingredients or raw materials, or partially prepare the products with labor from outside the region, and do not disclose these facts to consumers who purchase the products believing that they originate in their entirety from the region.

Thus, based on the assumption that Article 22(2) of TRIPS could be invoked also to prohibit the misleading use of GIs by GI producers, a solution that could potentially address the geographical inaccuracy, or inconsistency, and the (at least partial) lack of transparency of the current system could be the following: GI producers could be required to clearly disclose the actual geographical origin of any raw materials, ingredients, and manufacturing steps of the products that do not originate from the GI region at the point of sale and on the packaging of their products.

In particular, Article 22(2) of TRIPS could be interpreted as providing that, should producers not disclose this information to consumers in a transparent and explicit manner, GI producers may then be held accountable for using GIs "in a manner which misleads the public as to the geographical origin of the goods" and thus denied the right to use the said GIs. To the contrary, when producers disclose the actual origin of any raw materials, ingredients, and manufacturing steps of the products that do not originate from the GI region, they would be seen as complying both with Articles 22(1) and 22(2) of TRIPS, or more precisely their equivalent provisions in the national jurisdictions where the GIs are registered and/or protected. In practice, information about the quality and actual origin of the ingredients and raw materials used for the products may already be listed in the product specification, even though it is unclear if national laws require such disclosure as a requirement for registering GIs. ${ }^{116}$ Moreover, consumers rarely consult product specifications, if they are aware of the existence of these specifications at all. Instead, consumers generally rely on the information that they can find directly on the product packaging and

116 For example, the specification of the PDO "Prosciutto di Parma" permits that the pigs used for the final products, the Parma ham, originate from outside the Parma region, precisely from eleven different regions of Italy. Notably, "[t]he raw material comes from a geographical area that is larger than the production area, and which includes the administrative districts of the following Italian Regions: Emilia-Romagna, Veneto, Lombardy, Piedmont, Molise, Umbria, Tuscany, Marche, Abruzzo and Lazio (Italy)." See Specification and Dossier Pursuant to Article 4 of Council Regulation 2081/92 of July 14, 1992, on the Protection of Geographical Indications and designations of Origin for Agricultural Products and Foodstuffs, 1992 O.J. (L 208) 6, www.prosciuttodiparma.com/pdf/en_UK/disciplinare.28.11 .2013.en.pdf. 
advertising. ${ }^{117}$ Accordingly, by requiring producers to fully disclose the geographical origin of raw materials, ingredients, and manufacturing steps on the packaging on the products and related product advertising consumers would be made aware of the actual origin of all these various components. This not only would allow consumers to make better informed purchasing decisions; it would also incentivize GI producers to select materials, ingredients, and human factors of a quality on par with the reputation of the products, lest consumers may no longer purchase the GI products.

Equally relevant, this obligation could benefit the producers in the localities from which the raw material ingredients originate, or the workers that provide some of the manufacturing steps of the products. Today, these producers and workers disappear in the production chain of the GI products, and their work is not at all recognized even though their role in the final quality, and the overall success of the products, cannot be overstated - simply put, there would not be Swiss chocolate without cocoa beans from cocoa plantations that are certainly not located in Switzerland. ${ }^{118}$ This observation is of particular importance for countries that are primarily producers and exporters of agricultural products, and in particular for developing countries, including developing countries in Asia-Pacific - many of which have registered GIs for agricultural products. ${ }^{119}$ As noted also in a 2013 study, raw materials command a much lower premium price than finished products in general, ${ }^{120}$ and in countries whose GIs are primarily agricultural and raw-materials-based, GI

117 See, e.g., Annette Kur, Quibbling Siblings: Comments to Dev Gangjee's Presentation, 82 CHI.KENT. L. REV. 1317, 1320-321 (2007) (noting "[a]s most of us are laymen in the field, we have to trust the competent authorities to do their job correctly" and that "the informing effects that protected GIs have on consumers resulting from the fact that the products bear, in addition to the GI itself, the indications 'PDO' ..., 'PGI' ..., or their equivalents in other languagesappear modest at best").

118 Ammini Ramachandran, Indian Cocoa Grown for Swiss Chocolate, Zester Daily (June 21, 2012), http://zesterdaily.com/agriculture/indian-cocoa-grown-for-swiss-chocolate/ (stating that Swiss Chocolat Noir is made from cocoa from Kerala, India). Kaspar Meuli, Facing Cocoa Shortage, Swiss Chocolate Makes Aim to Boost African Production, WorldCrunch (January 2, 2012), http://www.worldcrunch.com/business-finance/facing-cocoa-shortage-swis s-chocolate-makers-aim-to-boost-african-production (stating that " $[\mathrm{m}]$ ore than half of the cacao beans transformed into chocolate in Switzerland come from [Ghana]").

11 An analysis of the GIs that are registered in ASEAN indicates that a large part of these GIs comprises of agricultural products, such as pineapples, rice, sugar coffee, tea, etc. See ASEAN GI Database, www.asean-gidatabase.org (last visited August 22, 2016).

120 Areté, supra note 86, at 6 (this study was commissioned by the EU Commission and proves, with data, that "[a]s for agricultural raw materials, price premiums for raw materials for GI production were very limited or absent in the majority of cases. Significant price premiums for GI production over standard production were observed in less than one third of the cases"). 
producers do not seem to receive a fair share from the current GI system compared to the producers of fully developed GI products. Instead, processed products, like wine and cheese, tend to enjoy higher premium prices over competing products, even when they are made, in part, with foreign ingredients - again the case of Swiss chocolate is on point. ${ }^{121}$ In this respect, a more transparent system of GI protection requiring full disclosure would both be compatible with the current language of TRIPS and make a stronger case in support of GI protection everywhere.

\section{CONCLUSION}

This chapter highlighted how the debate over GI protection remains controversial under multiple fronts. Notably, as the title of this volume summarizes, GIs are today at a crossroads between trade, development, and culture-related interests. In particular, this chapter illustrated how the GI debate, and related controversy, continues to dominate international trade negotiations - at this time no longer (or not only) under the umbrella of the WTO, but primarily as a topic addressed in bilateral and multilateral FTAs. Moreover, attention to GIs is no longer just a "European thing," even though the EU has largely built its trade negotiations' agenda over obtaining protection, or enhancing the existing protection, for its GIs. Instead, many countries outside the EU, including in Asia-Pacific, have turned their attention to GIs and implemented national systems of GI protection driven by the beliefs (and hopes) that this could promote local development as well as assist marketing their products in the global market. Hence, this chapter has also highlighted that GIs do not represent, per se, a magic tool for local development. Thus, a wise development strategy should always include strict quality control protocols, long-term plans to maintain product quality, and thoughtful marketing strategies.

While highlighting the economic benefits of GI protection, this chapter also emphasized that GIs should not become pure marketing tools for GI producers. In this respect, it argued that the current definition of GIs has drifted toward a looser linkage between GIs and their historical justification: the territorial linkage between the products and the regions. Notably, GI protection today extends to products that only "essentially" originate from GIdenominated regions, which permit producers to partially (or mostly) outsource the raw materials, ingredients, or manufacturing steps of GI products, and still enjoy exclusive rights on the GI names. This chapter criticized this 
development as not being in line with the normative justifications for GI protection and possibly a violation of Article $22(2)$ of TRIPS. Instead, this chapter supported a narrower definition of GIs to reflect a closer linkage with the terroir, with this link implemented in the form of a requirement that GI producers disclose the actual origin of all the raw materials, ingredients, and manufacturing steps of the GI products to consumers at the point of sale, and on the product packaging and advertising. This requirement is compatible, and perhaps even mandated, under a sensible interpretation of Article 22(2) of TRIPS, and would benefit a more transparent system of GI protection, both to the advantage of producers - GI producers and the producers of the foreign materials, ingredients, and labor of GI products - and consumers. 